\title{
The use of automated systems to improve quality control of energy consumption
}

\author{
$D I$ Gataullin* and $R R$ Vildanov \\ Kazan State Power Engineering University, Krasnoselskaya st., 51, Kazan
}

\begin{abstract}
To effectively plan of energy saving and energy efficiency measures, it is necessary to take account of energy consumption. However, this leads to an increase in the number of metering stations, which in turn leads to additional human and material costs for their maintenance, as well as the collection and processing of information from the devices installed on them. The ability to automate these works is the most profitable solution. In this paper, the ACEAS installed in the KSPEU was considered. Its work from April to May 2019 was analyzed.
\end{abstract}

\section{Introduction}

Despite the fluctuation in energy prices, the growth of tariffs for thermal and electric energy remains unchanged. Against this background, interest in energyefficient and resource-saving technologies is not fading [1]. To date, their implementation is one of the most important priorities of socio-economic development in the global, national and regional dimensions [2].

Improving energy efficiency is a prerequisite for competitiveness and the main motivation to achieve energy efficiency indicators through the modernization of equipment, the use of new technological solutions, as well as the introduction of organizational measures [3].

This requires a significant amount of preparatory work, energy audits in particular, which would allow to answer the questions:

- what is the effectiveness of the implementation of energy efficient measures for a particular object?

- what is the cost of implementing the measures? [4]

To facilitate this audit, it would be appropriate to introduce automated commercial energy accounting systems (ACEAS).

It should be noted that in order to improve the quality and efficiency of heat supply, it is necessary not only to update the fleet of existing equipment, to change the circuit-technological solutions, but also to optimize the heat market itself [5]. Therefore, in modern economic conditions, commercial relations between the supplier and consumers of energy play an important role. For example, in the regions of the far North there aren't many installed heat meters or no at all. Therefore, both indicators of thermal energy production and indicators of its consumption are mainly calculated values, and calculations for thermal energy are still carried out according to standards, and not according to real consumption [6]. The increase in devices and heat metering units leads to additional human and material costs for their maintenance, as well as the collection and processing of information from the devices installed on them. However, the introduction of ACEAS solves this problem.

This system also helps the wholesale electricity and power market players in forecasting electricity consumption [7].

ACEAS should be understood as a system that allows to accounting of all energy carriers used in the enterprise or in the residential sector, with the division of this accounting by territorial or functionally allocated sites metering station (MS). In addition, it allows:

a) to estimate the share of each energy carrier in the allocated MS concerning the General consumption of the corresponding energy resource by the enterprise;

b) perform calculation on actually consumed energy resources by each territorially or functionally allocated sites of the enterprise and the enterprise as a whole;

c) evaluate the effectiveness of measures aimed at saving energy resources;

d) reduce operating costs and, as a result, increase the efficiency of the primary accounting systems in use;

e) evaluate the current status and efficiency of the metering devices;

f) determine the main directions of energy saving activities [8].

It should be noted that the potential of energy-saving technical solutions and measures in the housing and communal services of Russia is also huge [9]. Therefore, even now this issue is becoming more urgent. Another reason for this is the transition to environmental management. In order to provide favorable conditions for the progressive development of energy saving in the housing and communal sector, it is necessary to carry out commercial accounting of energy resources, which allows to present the current situation on the introduction of resource saving in the activities of management companies. This analysis, based on planned and actual

*Corresponding author: m_d_g_96@mail.ru 
data, provides a quantitative and qualitative assessment of changes in the management object, and also helps to make management decisions aimed at eliminating the causes of negative deviations [10].

The ultimate goal of energy saving is to reduce the cost of the subscriber to pay for energy resources. Consumers of electricity have a resource to reduce costs by eliminating the payment of fines for violations of the contractual consumption schedule. Therefore, they are interested in having tools to monitor current consumption and predict its future values [11].

Automated systems of commercial accounting have been used for a long time in industrial enterprises, and today with increasing intensity — in the municipal sector [12]. This was due to the fact that the housing sector is complex enough to cover energy accounting systems. This is especially true for apartment buildings. Therefore, today ACEAS are more actively established in cottage settlements, than in high-rise buildings. Through each metering point in the cottage settlement passes a more powerful flow of electricity and heat than through the meter in the apartment. So the installation of ACEAS in the cottage allows you to get a more significant effect of savings. In fairness, it should be noted that some experts doubt whether it is possible in today's conditions to obtain a significant effect from the installation of ACEAS in a high-rise building. The fact is that the issue of apartment-based automated accounting is not yet sufficiently regulated in terms of legislation. It is difficult to define a customer who is interested in creating ACEAS. Whether it is management or energy sales companies, or residents. Therefore, ACEAS is now installed mainly in new buildings, which are often not taken into operation without a system of apartment accounting. That is to say, that it is not so much about a possible economic effect as a direct administrative pressure on the developer. However, it should be noted that the are more and more exceptions of this rule [13].

Another main problem of modern energy is the theft of energy resources, especially electricity. The damage from actions of "energy thieves" nationwide is calculated in billions of rubles. According to experts, in 2010, the loss of electricity in the networks amounted to about 130 billion $\mathrm{kW}$. Most of the losses are the result of underaccounting and theft of electricity, overflowing the power grid complex of our country in recent years. "Only according to official data, about $10 \%$ of electricity is stolen in Russia every year [14]. For the past ten years modernization of the technical equipment, the improvement of measurement process and systems of accounting of power consumption in the electric industry was happening at a fast pace [15]. The introduction of ACEAS enabled the identification of non-payers, thereby significantly reducing unaccounted energy consumption.

\section{Methods}

Further, we consider the automated system of commercial accounting installed in the academic buildings and dormitories of the Kazan State Power Engineering University.

The block diagram of ACEAS is shown in Pic. 1.

The system consists of the following levels:

1. Lower level presented to the metering devices of
Student dormitory № 1 (The second South West 26)

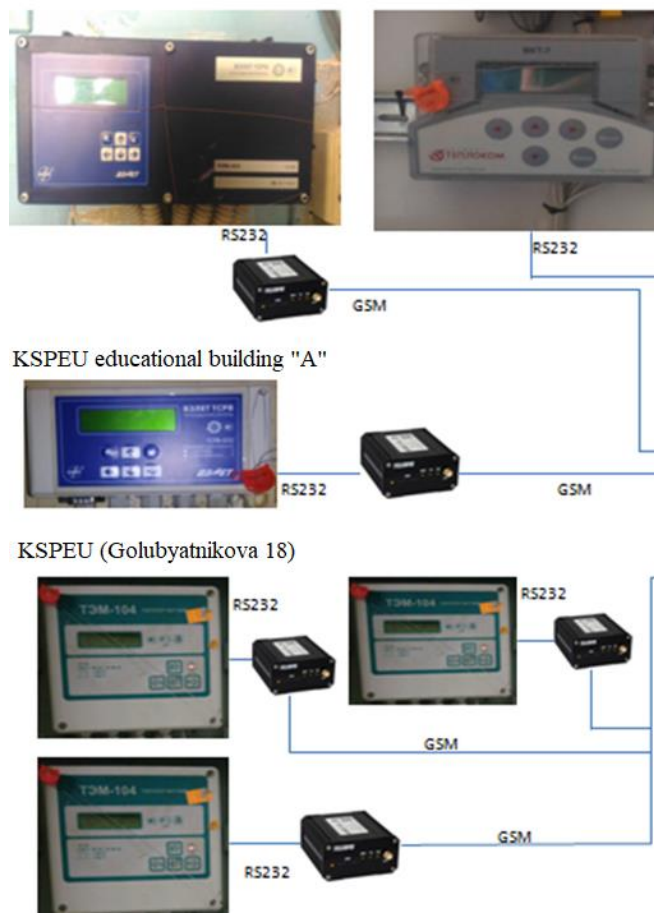

Student dormitory № 2 (The second South West 26a)

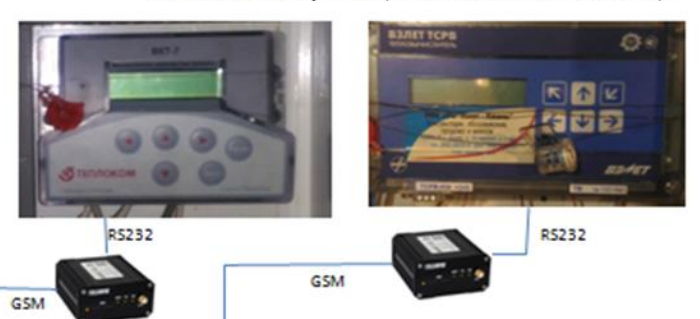

Student dormitory № 3 (Yarullin 6)
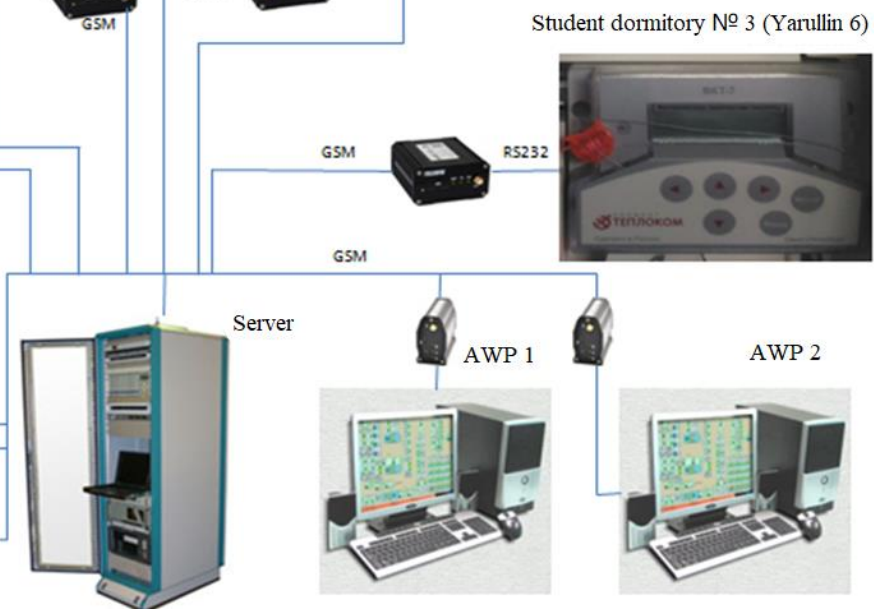

Fig. 1. Diagram of the ACEAS system installed at KSPEU. 
thermal energy companies "Teplokom" and "Vzlet".

2. The middle level includes channel-forming equipment, namely GSM Teleofis RX100-R4 (H) modem in the amount of 5 pieces, installed directly at the metering points for data transmission.

3. The upper level is represented by automated workstations consisting of:

a) GSM/GPRS Modem brand MUR1001.9 TLT installed on the APM 1 and 2.

b) Software " Energoresury " produced by STC "ARGO", Ivanovo.

One APM is located in the classroom for the possibility of laboratory work, the second - in the office of the main power KSPEU power engineer.
All used equipment and software are included in the state register of the Russian Federation as approved types of measuring instruments

\section{Results}

For figure 2 and 3 there is presented a graphical report on the heat consumption of the hostel №2 and №3 of Kazan State Power Engineering University from April to May 2019.

The graph shows how the heat consumption of both dormitories went down after April 25, which could mean the end of the heating season. When comparing the dynamics of changes in the heat consumption of the two

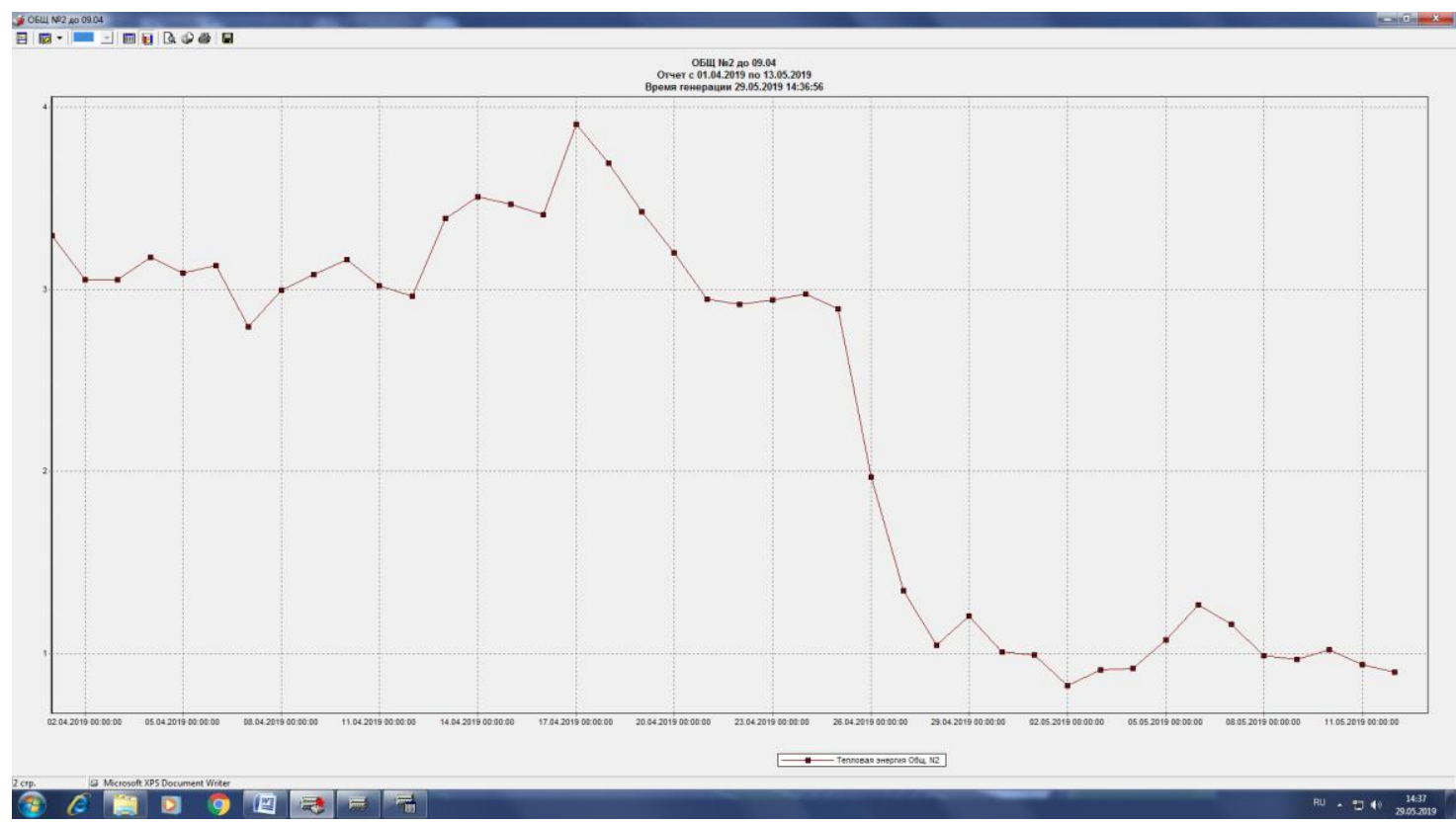

Fig. 2. Graphical image of the report of heat energy consumption by the dormitory №2 .

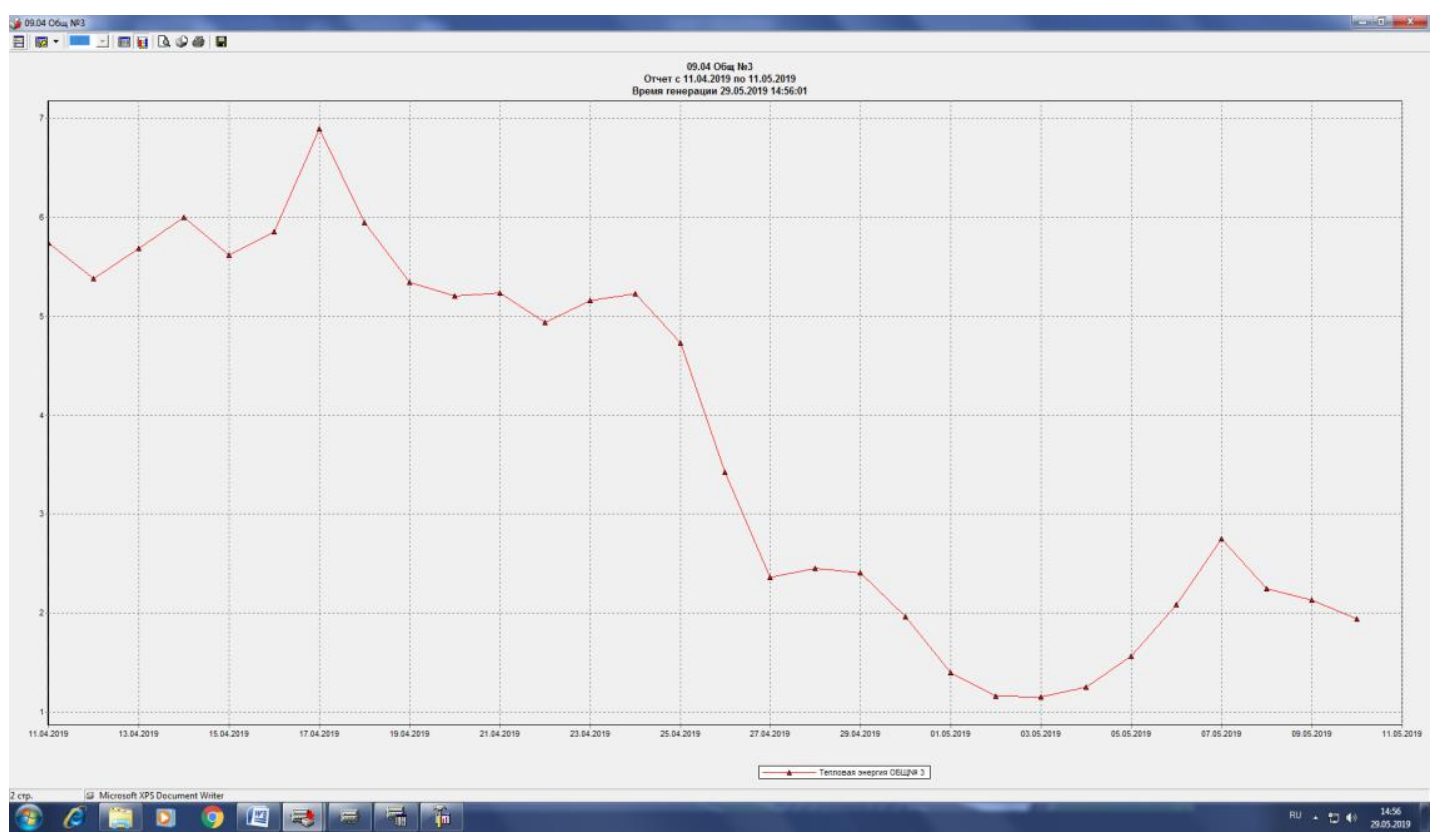

Fig. 3. Graphical image of the report of heat energy consumption by the dormitory №3. 
dormitories, no strong deviations were observed, which indicates the correct operation of energy metering devices. The graphs also show that energy consumption increased slightly on May $6-7^{\text {th }}$. Since the nature of the changes repeat each other again, we conclude that it is not the fault of the devices, but the decrease in the outside air temperature. which optimizes commercial relations with heat suppliers. Also, the data obtained with the help of this system can help in thinking through energy-saving measures, as well as in their evaluation

\section{References}

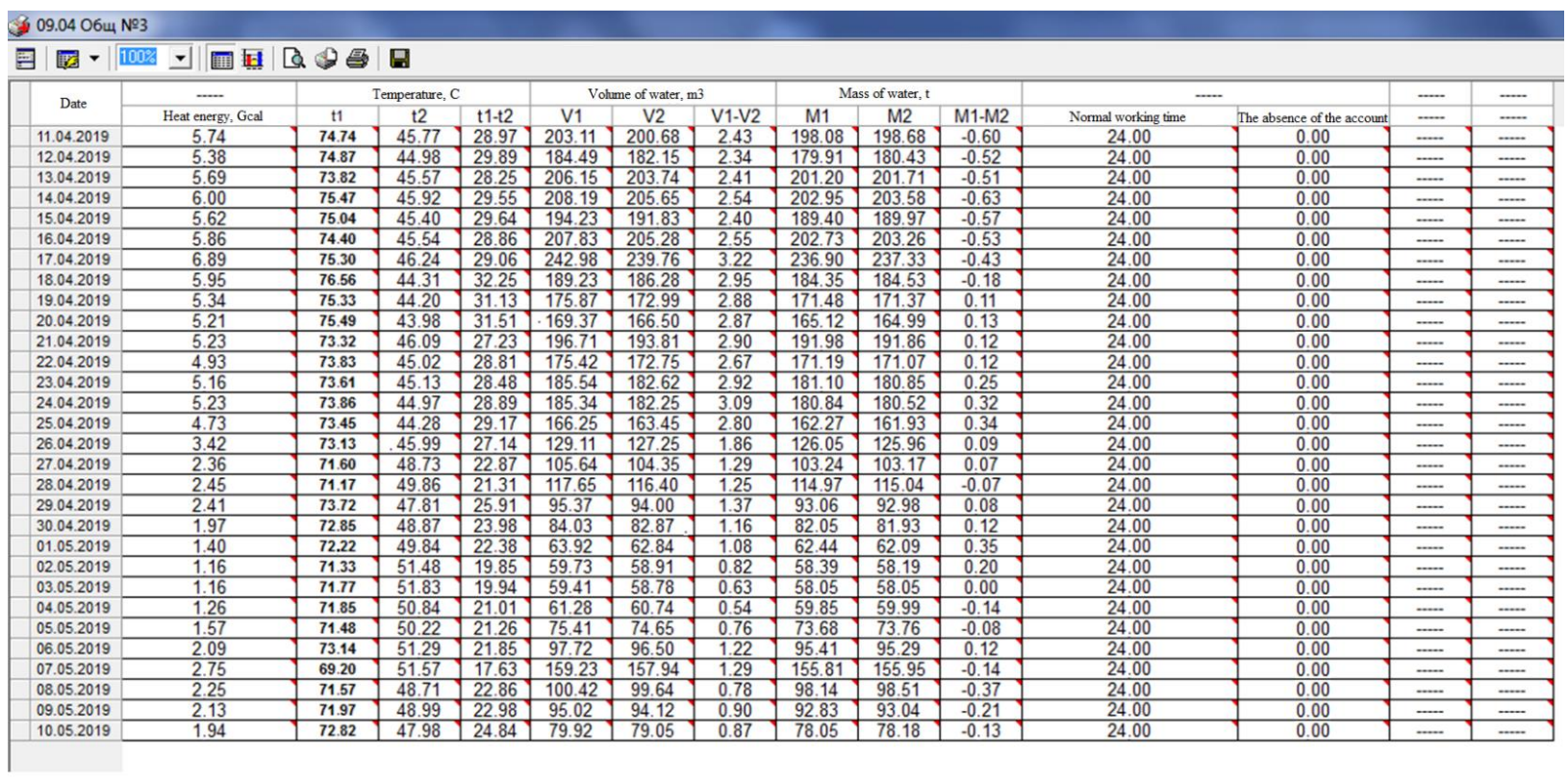

Fig. 4. Data on the heat carrier in the heat supply system.

ACEAS allowed us to monitor the operation of the equipment in the dormitories, as well as to fix the end of the heating season. Another advantage of this system is the ability to record not only the daily energy consumption, but also hourly, which can help in choosing energy pricing.

It should be noted that the reporting form of the software allows to obtain not only data on heat consumption, but also the parameters of the heat carrier in the heat supply system. Data on the heat carrier are presented in figure 3 .

Since one of the workstations was installed in the classroom, it became possible to introduce laboratory work into the curriculum, which makes it possible to train students on existing automated accounting systems used in modern energy. Also, students will have the opportunity to get more information about the operation of the heat and power supply system and better influence of outdoor air on the parameters of energy carriers.

\section{Conclusions}

To sum up, the automated system allows you to remotely monitor energy consumption from a variety of points, eliminating the visual collection of data from the meters. The advantage of ACEAS should include the ability to monitor the condition of the equipment on the MS, to fix all faults and emergencies. In addition, ACEAS provides a one-time collection of data from metering devices, (-ven,

6. D.I. Karabarin, S.A. Mihajlenko, Improving energy efficiency of energy production in decentralized energy areas, Izvestiya Tomskogo Politekhnicheskogo Universiteta. Inzhiniring georesursov, 10, 81-86 (2017)

7. V.I. Potapov, A.S. Gricaj, D.A. Tyunkov, G.E. Sinicin, Use of a neural network to build a shortterm forecast of power consumption of Omsk power supply company LLC, Izvestiya Tomskogo Politekhnicheskogo Universiteta. Inzhiniring georesursov, 8, 44-51 (2016)

8. V.S. Kazachkov, A.Y. Yaskin, Accounting of thermal energy at the enterprises of railway transport on the basis of AMR, Vestnik transporta povolzh'ya, 1(17), 28-33 (2009)

9. F.R. Muhamedsharipov, Trends in the development of automated systems of commercial accounting of energy resources, Mir izmerenij, 10,26-27 (2011)

10. A. Larionov, Y. Larionova, L. Selivanova, Regional Peculiarities of Energy Saving Development During the Exploitation of Housing and Underground Housing and Utility Sector Objects, Procedia Engineering, ,165, 1229-1232 (2016)

11. L.A. Delegodina, Forecast of energy consumption in the AMR NSC artificial neural network, Problemy informatiki, 1(13), 66-72 (2012)

12. M. Myakochina, The architecture of AMR system on the basis of the decisions of the company 
Milandr, Komponenty i tekhnologii, 5(166), 108111 (2015)

13. G.I. Vintin, AMR for the private sector, Energiya: ekonomika, tekhnika, ekologiya, 9, 74-79 (2011)

14. S.I. Kirillov, O.G. Bershadskij, Theft of electricity as a problem in the energy system and measures to minimize it in modern Russia, Vestnik moskovskogo universiteta MVD Rossii, 2, 50-52 (2018)

15. A.A. Chuhrov, Analysis of non-technical power loss detection methods, Sistemnyj analiz v nauke i obrazovanii, 4, 43-49 (2015) 